\title{
O caderno cibernético de José Saramago: peças soltas de uma autobiografia
}

Andre Luiz Amaral 1

\begin{abstract}
RESUMO: Este artigo analisa as continuidades e descontinuidades partilhadas pela biografia e autobiografia, diários íntimos e blogs. A indissociabilidade entre a vida e a obra de um autor caracteriza a tema central do texto. Essas questões são discutidas à luz do livro/blog O caderno, escrito pelo romancista português José Saramago.
\end{abstract}

ABSTRACT: This article analyses continuities and discontinuities shared among biographies and autobiographies, personal journals and blogs. The indissociable character between the life and the work of an author characterizes the central theme of the text. These questions are discussed based on the book/blog O caderno, written by the Portuguese novelist José Saramago.

PALAVRAS-CHAVE: Blog; Diário íntimo; Autobiografia; Performance; José Saramago KEYWORDS: Blog; Personal journal; Autobiography; Performance; José Saramago

"Tudo é autobiografia" (José Saramago, Manual de pintura e caligrafia)

A matriz do gênero literário biografia é o encômio, isto é, a apresentação elogiosa ou quase heroica da vida de uma pessoa. Em geral, seguia-se a ordem cronológica (origem; formação e profissão; atos). Muito utilizado no mundo helenístico e bastante aproximado da hagiografia, o encômio, com o passar dos séculos, deu lugar a modelos mais complexos, como os evangelhos, que em certa medida podem ser considerados biografias laudatórias. (BERGER, 1998, p. 313). As biografias antigas tinham caráter mítico-cultual (p. ex. Vida de Apolônio e Vida de Teseus), e não costumavam dar grande importância aos elementos cotidianos. Como afirma Marília Cardoso,

\footnotetext{
${ }^{1}$ Mestrando da UFSC.
} 
muitos dos valores-referência da cultura do ocidente foram-se consolidando, ao longo dos séculos, através de relatos, onde a trajetória de homens ilustres monarcas e santos - encadeava-se por meio de imagens, tropos e outras formas lingüisticas convencionais (CARDOSO, 2002, p. 112).

Depois da ascensão do gênero na Idade Média, a partir das confissões autobiográficas, como as Confissões de Santo Agostinho, houve um longo período de ocaso até o ressurgimento, com a arte iluminista, no século XVIII. Ainda grande parte das biografias é formada por verdadeiras elegias, mas, na pós-modernidade, a situação é peculiar, pois é possivel escrever uma biografia "não-autorizada", que pretensamente conte partes obscuras da vida de alguém famoso:

$\mathrm{Na}$ "condição pós-moderna" de descrédito das grandes narrativas, a biografia perde seu lugar no plano da alta cultura, para galgar o posto de best-seller no circuito mercadológico. Atletas, cantores pop, atores de TV, empresários juntam-se aos escritores e artistas, no amplo estoque das figuras biografáveis. (CARDOSO, p. 113)

Octavio Paz escreveu na primeira linha do ensaio " $O$ desconhecido de si mesmo - Fernando Pessoa", em 1961, que "os poetas não têm biografia. Sua obra é sua biografia” (PAZ, 2006, p. 201). No parágrafo seguinte ele não se contém e narra a vida de Pessoa: "Nasce em Lisboa, em 1888. Criança, fica órfão de pai. Sua mãe volta a casar-se; em 1896 transfere-se com os filhos, para Durban, África do Sul ..." (PAZ, p. 202). Não demorou muito para que Paz percebesse a biografia e a obra de um escritor como indissociáveis, embora a vida não se resuma ao que está escrito.

Tal indissociabilidade torna-se evidente quando um autor de reconhecido destaque como o português José Saramago confere valor ao gênero (auto)biográfico. Ele esboçou uma autobiografia ficcional no Manual de pintura e caligrafia. Ao que tudo indica, o percurso do personagem $\mathrm{H}$. se parece em muito com o do próprio autor, que com esse livro inicia nova fase em sua obra: 
O que vemos no Manual é um JS escritor, disfarçado sob a capa do personagem, dramatizando a crise de ser escritor de uma época marcada por escritas neo-realistas, numa busca pela cópia perfeita da realidade. Contudo, a consciência quanto à limitação das palavras em abarcar a realidade o leva a admitir, em certa medida, sua presença na romance autobiográfico ao declarar "logo este primeiro exercício de autobiografia dissimulada me denuncia”. (ROLIM, 2009)

A incursão autobiográfica mais direta e explícita do autor está nos Cadernos de Lanzarote, escritos de 1993 a 1997 a pedido de amigos e familiares. ${ }^{2}$ Mas um diário é uma autobiografia? Caso nos posicionemos de maneira dogmática, o diário não é uma autobiografia. Obedece a um acordo, uma lei. Sua regra principal é a data, em geral no topo da página, “o calendário é seu demônio”, diria Blanchot (2005, p. 270). Serve para conservar a memória e diz respeito, em suma, à intimidade do sujeito. Ninguém, a priori, escreve um diário íntimo com os olhos voltados para o mercado literário. Isso seria burlar a norma, conforme afirma Philippe Lejeune:

Uma entrada de diário é o que foi escrito num momento, na mais absoluta ignorância quanto ao futuro, e cujo conteúdo não foi com certeza modificado. Um diário mais tarde modificado ou podado talvez ganhe algum valor literário, mas terá perdido o essencial: a autenticidade do momento. Quando soa a meia-noite, não posso mais fazer modificações. Se o fizer, abandono o diário para cair na autobiografia. (LEJEUNE, 2008, p. 260)

Se, ao contrário, entendermos a composição de um diário como uma proto-autobiografia ou mesmo como gesto autobiográfico, num ato performático e vital, concordaremos com Marcello Matias, para quem "a

\footnotetext{
2 Outra autobiografia saramaguiana, cuja composição foi anunciada nos Cadernos sob o título "Livro das tentações", é fragmentária e não menos ficcional que as demais. Trata-se de As pequenas memórias, narrativa da infância do autor na aldeia de Azinhaga.
} 
autobiografia é una; o diário sempre é plural, e constrói-se de mil e uma breves autobiografias, sempre repetidas e inacabadas" (MATIAS, 1997; p. 46). Portanto, está longe de ser a compensação de uma dupla nulidade, como analisa Blanchot: "Aquele que nada faz de sua vida, escreve que não faz nada, e eis, apesar de tudo, algo de feito" (BLANCHOT, p. 274). Isso também percebeu José Saramago, com grande acuidade, no dia 23 de setembro de 2008:

Creio que todas as palavras que vamos pronunciar, todos os movimentos e gestos, concluídos ou somente esboçados, que vamos fazendo, cada um deles e todos juntos, podem ser entendidos como peças soltas de uma autobiografia não intencional que, embora involuntária, ou por isso mesmo, não seria menos sincera e veraz que o mais minucioso dos relatos de um vida passa à escrita e ao papel. (SARAMAGO, 2009, p. 30-31)

A data denuncia a escrita em diário, ou melhor, em blog. Um blog é uma página virtual na qual um ou mais autores deixam suas mensagens. Segundo Tânia Ramos, "esta página virtual e interativa tem muitas vezes conteúdo de diário, e pode-se ler de tudo num blog. De política ao fim de um relacionamento. Do primeiro beijo à descrição de um filme clássico" (RAMOS, 2008, p. 162). Os visitantes de um blog podem deixar comentários sobre os textos - ou posts -, que são ordenados pela data de entrada na página. A mais recente aventura autobiográfica de José Saramago chama-se O Caderno de Saramago, blog mantido pela Fundação José Saramago (http://www.josesaramago.org), e com versões em português (http://caderno.josesaramago.org/) e espanhol (http://cuaderno.josesaramago.org/). Semelhante aos Cadernos, esse Caderno virtual teve início a pedido de amigos e familiares em setembro de 2008.

Víctor Martínez, da Universidade San Jorge (Zaragoza/ESP), realizou análise de dados de vinte blogs de autor em lingua espanhola. Dentre as diversas páginas, foi abarcada a versão em espanhol do 
Caderno. Martínez observou que o blog não possibilita aos visitantes enviar comentários sobre os textos postados, impressão de textos, enviar a página a amigos ou enviar mensagem eletrônica ao autor, nem tampouco utiliza recursos multimídia (vídeos, imagens, sons) (MARTÍNEZ, 2009).O que faz, então, que a página alcance sucesso entre os leitores?

Os textos abordam os mais diversos assuntos: politica, religião, sexualidade, cotidiano e, obviamente, as atividades do próprio Saramago. Aliás, sua vida está sempre imbricada nos relatos. Referindo-se ao primeiro ministro italiano, Silvio Berlusconi, no dia 19 de setembro de 2008, ele diz: "Sendo eu publicado em Itália pela editora Einaudi, propriedade do dito Berlusconi, algum dinheiro lhe terei feito ganhar". Também comenta sobre a adaptação de seu livro, Ensaio sobre a cegueira, em 28 de outubro de 2008. Em novembro do mesmo ano os relatos autobiográficos se tornam mais frequentes: "Há poucos minutos uma estação de rádio portuguesa quis saber qual seria a primeira medida de governo que eu proporia a Barack Obama..."; "Intento ser, à minha maneira, um estoico prático...". Nesse ritmo também se agrupam relatos de viagem: "De viagem para o Brasil..."; "Não foi fácil chegar ao Brasil..."; "No Brasil, entre entrevista e entrevista..."; "Continuamos no Brasil...”. E o autor não se furta a fazer propaganda de seus livros: "Esta tarde, na Academia Brasileira de Letras, apresentei A viagem do elefante..."; “Apresentei A viagem do elefante em Lisboa e aproveitei para dizer que a minha cabeça anda às voltas com um novo livro. Uf!".

O autor se despediu dos leitores do blog em 31 de Agosto de 2009, mas voltou a escrever na página em 11 de setembro do mesmo ano. O que foi escrito até 15 de março de 2009 resultou em livro. O célebre Umberto Eco escreveu no prefácio à versão publicada em italiano do Caderno, reproduzido na seção de opinião do Diário de Notícias, em Portugal: "Saramago não faz cerimónias, ou seja, não o manda dizer por outro e, na sua actividade de comentador diário da realidade que o 
rodeia, tira a desforra sobre toda a imprecisão sinistra das suas fábulas". E ainda:

\begin{abstract}
Saramago blogger é um zangado. Mas haverá realmente um hiato entre esta prática de indignação diária sobre o transeunte e a actividade de escrita de "opúsculos morais" válidos tanto para os tempos passados como para os futuros? Escrevo este prefácio porque sinto ter alguma experiência em comum com o amigo Saramago, que é a de escrever livros (por um lado) e por outro a de nos ocuparmos de crítica de costumes num semanário. Sendo o segundo tipo de escrita mais claro e divulgador que o outro, muita gente me tem perguntado se eu não despejaria nas pequenas peças periódicas reflexões mais amplas feitas nos livros maiores. Não, respondo eu, ensina-me a experiência (mas creio que o ensina a todos os que se encontrarem em situação análoga) que é o impulso de irritação, a dica satírica, a chicotada crítica escrita à pressa, que fornecerá a seguir o material para uma reflexão ensaística ou narrativa mais desenvolvida. É a escrita diária que inspira as obras de maior empenho, e não o contrário. (ECO, 2009, grifo meu)
\end{abstract}

Ora, nos textos que constam no livro, percebe-se claramente que questões outrora buriladas à exaustão nos romances recebem nova atenção, apresentadas com um estilo mais direto. Menos barroco, digamos. Isso cria no leitor a impressão de proximidade, de intimidade, como quem lê um diário íntimo e descobre os segredos de outrem. De fato, "dentro da escrita virtual, o que importa para a formação de um público é mais o estilo que o diarista vai imprimir ao seu blog do que propriamente o quanto esse blog é capaz de informar do seu tempo e de sua história" (SCHITTINE, 2004, p. 25).

Em 25 de Novembro de 2008, Saramago registrou no Caderno suas impressões de uma entrevista coletiva concedida em São Paulo. Apesar do anúncio de uma "exposição estupenda" no Instituto Tomie Othake e do lançamento de um novo livro à vista, o jornalistas lhe perguntaram sobre a decisão de escrever "na infinita página da 
internet”. A partir deste acontecimento, conjectura sobre a função dos blogs, incluindo o seu:

Será que, aqui, a bem dizer, nos assemelhamos todos? É isto o mais parecido com o poder dos cidadãos? Somos mais companheiros quando escrevemos na internet? Não tenho respostas, apenas constato as perguntas. E gosto de estar escrevendo aqui agora. Não sei se é mais democrático, sei que me sinto igual ao jovem de cabelo alvoroçado e óculos de aro que, com os seus vinte e poucos anos me questionava. Seguramente para um blog. (SARAMAGO, p. 121)

Ele parece estar certo em suas impressões sobre a proximidade com os leitores de seu blog, pois eles se identificam com as ideias do escritor, sentem que lhe são íntimos. Ao contrário do que acontece nos diários à moda antiga, nos blogs "a fronteira entre autores e leitores se torna móvel e permeável" (SCHITTINE, p. 95). Muitos, mesmo sem nunca terem lido romances como $O$ evangelho segundo Jesus Cristo, História do cerco de Lisboa ou Levantado do chão, são leitores assíduos e verdadeiros fãs do Saramago blogueiro. Talvez, pela máxima de Umberto Eco: "É a escrita diária que inspira as obras de maior empenho, e não o contrário". Por isso, o público de O caderno não é necessariamente o mesmo que o dos romances, pois nele Saramago se aproxima da crônica. Lembremos que Saramago escreveu o romance Terra do pecado em 1947, sem obter grande sucesso. Em 1966 enveredou-se pela poesia, com Os poemas possiveis, seguido de Provavelmente alegria, em 1970. A estes livros sucedem Deste mundo e de outro, em 1971; A bagagem do viajante, em 1973; As opiniões que o DL teve, em 1974; e Os apontamentos, em 1976, todos de crônicas. ${ }^{3}$ Trata-se, sobretudo, do retorno ao estilo original, e não de uma novidade na obra do autor. No blog, o estilo da escrita dilui as fronteiras entre o romancista premiado e o leitor atento. Firma-se, então, um pacto.

${ }^{3}$ Neste interim foram publicados o conto "O embargo", em 1974, e texto experimental O ano de 1993, em 1975. 
Voltemos, com isso, ao problema da autobiografia como gesto. No ensaio "O autor como gesto", Agamben retoma a conhecida conferência de Foucault “O que é um autor?” para trazer à tona dois importantes conceitos: autor como individuo real e a função-autor. Em linhas gerais, significa dizer que apesar da existência inegável do autor como sujeito, ele está ausente. $\mathrm{Na}$ função-autor o individuo está vinculado ao corpus literário que produziu e "toda a investigação sobre o sujeito como indivíduo parece ter que ceder lugar ao regesto, que define as condições e formas sob as quais o sujeito pode aparecer na ordem do discurso" (AGAMBEN, 2007, p.57). Neste regesto - coletânea de escritos variados - o autor aparece apenas, ou especialmente, como gesto, como "o que continua inexpresso em cada ato de expressão" (AGAMBEN, p. 59). Assim como o autor põe em jogo, em sua obra, vidas reais e inventadas, ele mesmo se insinua nesse jogo, embora permaneça às escuras, sem se revelar de todo. Isso ocorre através do principal dispositivo que tem à mão, a linguagem. O sujeito-autor, lançando-se em jogo na linguagem, "exibe em um gesto a própria irredutibilidade a ela" (AGAMBEN, p. 63). Diante disso, podemos retornar ao conceito de autobiografia esboçado por Saramago e já citado aqui. O autor constrói sua autobiografia através de uma performance, de maneira não intencional, por meio da linguagem. Nesse sentido, cabe-nos citar a análise de Daiana Klinger:

O conceito de performance deixaria ver o caráter teatralizado da construção de imagem de autor. Desta perspectiva, não haveria um sujeito pleno, originário, que o texto reflete ou mascara. Pelo contrário, tanto os textos ficcionais quanto a atuação (a vida pública) do autor são faces complementares da mesma produção de uma subjetividade, instâncias de atuação do eu que se tencionam ou se reforçam, mas que, em todo caso, já não podem ser pensadas isoladamente. $\mathrm{O}$ autor é considerado como o sujeito de uma performance, de uma atuação, um sujeito que "representa um papel" na própria "vida real", na sua exposição pública, nas suas múltiplas falas de si, nas entrevistas, nas crônicas e auto-retratos, nas palestras. (KLINGER, 2007, p. 54-55) 
Como em toda performance, a atuação de um autor pressupõe interação com espectadores/leitores. Em suma, nunca há plateia passiva, mas co-performers, cujos gestos imprimem no autor uma transubjetividade, pelo que nunca se verá um auto-retrato do autor, observa Lejeune, mas uma caricatura, quiçá mal desenhada (LEJEUNE, p. 296). O autor jamais atuará/escreverá isoladamente, mas em conjunto, em confronto e contato com os leitores. Por isso, os blogs, em maior ou menor grau, implicam numa dimensão ética, da qual não se pode fugir:

No universo dos blogs, todos são performers e ao mesmo tempo plateia, engajados em situações onde ora falam de suas experiências, assumindo diante da sua audiência a responsabilidade de expressá-las de modos socialmente aceitáveis em relação aos contextos em que estão inseridos, e ora interpretam e avaliam as expressões dos outros. Nas performances narrativas desenroladas nos blogs, eventos narrados e eventos narrativos se unificam, bem como o espaço e o tempo do narrador, do blogueiro, encontram-se com o espaço e o tempo da audiência em situações interativas, dialógicas e de troca de experiências que operam permanentemente na produção da cultura. Assim, as performances dos blogueiros são construídas colaborativamente [...]. (MÂXIMO, 2006, p. 110)

Uma escritura autobiográfica, como um diário, que seja composta colaborativamente é algo a se pensar. Será sempre fragmentária, imperfeita, dissonante. Logo, as palavras de um diário são peças soltas que se aglutinam não como as de um quebra-cabeça. É impossivel (re)montá-las de modo a criar um quadro nítido. Os diários ou blogs constituem autobiografias do desencaixe, sem a obrigação de estabelecer sentidos peremptórios. Isso porque relatam vidas em jogo, histórias em curso, e, portanto, nunca se acabam. Esse processo, no 
caso do Caderno de Saramago, não se encerrou nem mesmo com a publicação dos textos do blog em livro. Permanece na condição de work in progress, como a própria vida. ${ }^{4}$

\section{Referências bibliográficas}

AGAMBEN, Giorgio. Profanações. São Paulo: Boitempo, 2007.

BERGER, Klaus. As formas literárias do Novo Testamento. São Paulo: Loyola, 1998.

BLANCHOT, Maurice. O livro por vir. São Paulo: Martins Fontes, 2005.

CARDOSO, Marília Rothier. "Retorno à biografia" In: OLINTO, H. K.; SCHOLHAMMER, K. E. (orgs.). Literatura e Midia. São Paulo: PUC, 2002.

ECO, Umberto. "Um Blogger Chamado Saramago" In: Diário de Notícias, 07 de outubro de 2009. Disponivel em: http://dn.sapo.pt/inicio/opiniao/interior.aspx?content_id=1382926

GÓMEZ AGUILERA, Fernando. José Saramago: a consistência dos sonhos -cronobiografia. Lisboa: Caminho, 2008

KLINGER, Daiana Irene. Escritas de si, escritas do outro: o retorno do autor e a virada etnográfica - Bernardo Carvalho, Fernando Vallejo, Washington Cucurto, João Gilberto Noll, César Aira, Silviano Santiago. Rio de Janeiro: 7 letras, 2007.

LEJEUNE, Philippe. O pacto autobiográfico: de Rousseau à Internet. Belo Horizonte: UFMG, 2008.

MARTÍNEZ, Víctor Manuel Pérez. "El blog de autor: ¿nuevos horizontes para el Periodismo Literario en la Red?" In: Actas del I Congreso

\footnotetext{
${ }^{4}$ Embora não tenha sido nosso objetivo analisar relatos biográficos em torno do autor, duas importantes biografias de Saramago foram lançadas recentemente. A primeira, de Gómez Aguilera (GÓMEZ AGUILERA, Fernando. José Saramago: a consistência dos sonhos -cronobiografia. Lisboa: Caminho, 2008), contém muitas fotografias e é mais preocupada com as curiosidades da vida pessoal do biografado do que com sua obra. A segunda, recém-lançada, é de João Marques Lopes (LOPES, João Marques. Biografia - José Saramago. Lisboa: Guerra \& Paz; Pluma, 2009) e tem o foco voltado para a produção literária de Saramago. No site da Fundação José Saramago também é possivel encontrar dados (auto)biográficos.
} 
Internacional Latino de Comunicación Social, 2009. Disponivel em: http://www.revistalatinacs.org/09/Sociedad/actas/86victor.pdf

MATIAS, Marcello Duarte. "Autobiografias e diários" In: Colóquio/Letras, 143/144, pp. 41- 62, Jan., 1997.

MÁXIMO, Maria Elisa. Blogs: o eu encena, o eu em rede - Cotidiano, performance e reciprocidade nas redes sócio-técnicas. Florianópolis: UFSC, 2006. [Tese de Doutorado)

PAZ, Octavio. Signos em rotação. São Paulo: Perspectiva, 2006.

RAMOS, Tânia Regina de Oliveira. "Narrativas de si: lugares da memória" In: Revista do Programa de Pós-Graduação em Letras da Universidade de Passo Fundo, v. 4, n. 2, pp. 155-165, jul./dez. 2008

ROLIM, Michelle de O. "Memórias inventadas e vividas em José Saramago: entre a verdade e a ficção" In: Revista Crioula, n. 5, maio de 2009.2 Disponivel em: http://www.fflch.usp.br/dlcv/revistas/crioula/edicao/05/Dossie\%2 0-\%20Michelle\%20Rolim.pdf

SARAMAGO, José. As pequenas memórias. São Paulo: Companhia das Letras, 2006.

- Manual de pintura e caligrafia. 2. ed. São Paulo: Companhia das Letras, 1998.

. O caderno: textos escritos para blog setembro de 2008 - março de 2009. São Paulo: Companhia das Letras, 2009.

SCHITTINE, Denise. Blog: comunicação e escrita intima na internet. Rio de Janeiro: Civilização Brasileira, 2004. 